\title{
A TAXA DE RESPOSTA SUSTENTADA DA HEPATITE C CRÔNICA AO TRATAMENTO COM OS DIVERSOS INTERFERONS-ALFA E RIBAVIRINAS DISTRIBUÍDOS PELO GOVERNO BRASILEIRO É SEMELHANTE À DA LITERATURA MUNDIAL
}

\author{
Rafael Nastás ACRAS, Maria Lúcia A. PEDROSO, Leiber Carvalho CAUM, \\ Júlio C. PISANI, Heda M. B. S. AMARANTE e Eliane R. CARMES
}

\begin{abstract}
RESUMO - Racional - As taxas de resposta sustentada aos interferons-alfa 2A e 2B associados à ribavirina são descritas na literatura como sendo de $40 \%$. No entanto, a taxa de resposta sustentada em ambiente de freqüentes mudanças dos produtos fornecidos ainda não era conhecida. Objetivos - Avaliar a prevalência de resposta sustentada e os fatores preditivos de melhor resposta ao tratamento da hepatite $\mathrm{C}$ crônica, com as diferentes combinações e procedências de interferons-alfa e ribavirina, fornecidos pelo Ministério da Saúde e compará-la às da literatura mundial. Casuística e Métodos - Foi realizado estudo de coor te, não-controlado, em 87 pacientes do ambulatório de Hepatologia do Hospital de Clínicas da Universidade Federal do Paraná, Curitiba, PR, tratados com interferon-alfa e ribavirina, entre agosto de 1999 e agosto de 2002. Avaliou-se a prevalência de resposta sustentada e sua correlação com sexo feminino, idade, genótipos 2 e 3 e graus de fibrose. Resultados - Houve taxa de resposta sustentada em 32,1\% dos pacientes, correlacionada positivamente com os genótipos 2 e 3. Conclusões - As taxas de resposta sustentada encontradas são comparáv eis com as da literatura internacional, apesar das freqüentes variações quanto ao tipo e/ou procedência dos produtos.
\end{abstract}

DESCRITORES - Hepatite C crônica. Interferons. Ribavirina.

\section{INTRODUÇÃO}

Estima-se que existam no mundo todo 175 milhões de pessoas contaminadas pelo vírus da hepatite $\mathrm{C}(\mathrm{VHC})^{177}$. No Brasil, segundo dados da Organização Mundial de Saúde, $2,5 \%$ a $4,9 \%$ da população encontram-se infectada ${ }^{(11)}$. A hepatite $\mathrm{C}$ é considerada a principal causa de doença hepática bem como de transplante hepático nos Estados Unidos, podendo evoluir para cirrose (20\% a $40 \%$ dos casos) e carcinoma hepatocelular $(2,5 \% \text { dos casos })^{(3,16)}$
Pesquisas de tratamentos para a hepatite $\mathrm{C}$ aumentaram quando, em 1989, seu vírus foi isolado e identificado como o principal responsável pelas hepatites pós-transfusionais nãoA não-B ${ }^{(2)}$. Em 1997, um consenso americano ${ }^{(21)}$ estabeleceu o uso do interferon-alfa isolado para tratamento da hepatite $\mathrm{C}$ crônica. A resposta sustentada, compreendida como a ausência de RNA viral após 6 meses de tratamento era em torno de $20 \%(13,14,20,23)$. A taxa de resposta sustentada relaciona-se com a ausência do RNA viral por mais de $6 \operatorname{anos}^{(18)}$ em $92 \%$ dos casos e com a regressão da fibrose ${ }^{(25)}$. Respondedores ao

Serviço de Gastroenterologia do Hospital de Clínicas, Departamento de Clínica Médica, Universidade Federal do Paraná, Curitiba, PR Endereço para correspondência: Dra. Maria Lúcia A. Pedroso - Rua Coronel João Guilherme Guimarães, 183 - 80510-350 - Curitiba, PR. E-mail: malu.ap@uol.com.br 
tratamento têm baixo risco de desenvolver complicações decorrentes da hepatite $\mathrm{C}$ crônica, enquanto os não-respondedores têm pior prognóstico ${ }^{(15)}$. Em 1998, Consenso Europeu instituiu o uso de uma terapia combinada - interferon-alfa associado à ribavirina - sendo que a taxa de resposta sustentada elevou-se para $40 \%(13,14,19,20,24)$. Vários estudos determinaram que alguns fatores estão relacionados a melhor resposta ao tratamento com interferon-alf a e ribavirina: sexo feminino, idade inferior a 40 anos, fibrose leve ou ausência de fibrose, genótipos 2 ou 3 e carga viral menor que 3,5 milhões de cópias/mL $\mathrm{mL}^{(6,25,27)}$.

Desde 1999, o Ministério da Saúde do Brasil distribui a combinação desses medicamentos através das Secretarias de Saúde estaduais. Em 21 de junho de 2000 foi publicado um protocolo nacional regulamentando o tratamento da hepatite $\mathrm{C}$ crônica no Brasil $^{(1)}$, g arantindo à população o direito a este tratamento. Ocorre que a compra dos medicamentos pelo Ministério da Saúde é feita através de licitações que privilegiam os produtos de menor preço. Assim sendo, os for necedores podem ser laboratórios cujos produtos não tenham sua ef icácia comprovada. Este viés também faz com que freqüentemente ocorra a troca do tipo de interferon-alf a utilizado por um mesmo paciente, durante seu tratamento, ou seja, do tipo $2 \mathrm{~A}$ para 2B e/ou vice-versa. Questiona-se o quanto estes fatores poderiam contribuir para o insucesso do tratamento.

Desde 1999, o Hospital de Clínicas da Universidade Federal do Paraná (UFPR), em Curitiba, PR, trata pacientes portadores de hepatite $\mathrm{C}$ crônica com medicamentos fornecidos g ratuitamente pelo Ministério da Saúde, através da Secretaria de Saúde estadual.

O objeti vo principal deste estudo foi avaliar se a taxa de resposta sustentada em pacientes com hepatite $\mathrm{C}$ crônica, tratados no Hospital de Clínicas da UFPR com a associação interferon-alfa e ribavirina fornecidos pelo Ministério da Saúde, é comparável à da literatura inter nacional. O objetivo secundário é determinar fatores relacionados a melhor resposta ao tratamento.

\section{CASUÍSTICA E MÉTODO}

Foram considerados elegíveis para o estudo 102 pacientes com hepatite $\mathrm{C}$ crônica em tratamento no ambulatório de Hepatologia do Hospital de Clínicas da UFPR, que iniciaram o tratamento a partir de agosto de 1999 e em agosto de 2002 tinham tempo suficiente para avaliação da não-resposta ou da resposta sustentada.

Critérios de inclusão: 1) positividade pré-tratamento em, pelo menos, dois testes anti-VHC (ELISA) de segunda ou terceira geração e a determinação qualitativa do RNA do VHC (VHC-RNA) através do método da reação em cadeia da polimerase (PCR); 2) elevação da alanina aminotransferase (ALT) de 1,5 x o limite superior de normalidade, por duas opor tunidades, em 6 meses; 3 ) biopsia hepática nos últimos 12 meses, evidenciando atividade necroin- flamatória de moderada a intensa e/ou fibrose. Foram dispensados da biopsia somente os casos que apresentavam algum distúrbio hereditário de coagulação.

Todos receberam interferon-alfa na dose de 3 milhões de UI via subcutânea, 3 vezes por semana e ribavirina $1 \mathrm{~g}$ via oral por dia, conforme as diretrizes do Ministério da Saúde ${ }^{(1)}: 6$ meses de tratamento para os pacientes com genótipo 2 ou 3 e com dois ou mais itens de bom prognóstico (fibrose grau 0 ou 1, sexo feminino e idade inferior a 40 anos) e 12 meses para os demais. A medicação foi disponibilizada pela Secretaria de Estado da Saúde do Paraná. A procedência da medicação, segundo dados do Centro de Medicamentos do Paraná (CEMEPAR), da Secretaria de Estado da Saúde do Paraná, está discriminada nas Figuras 1 e 2. Ocorreu fornecimento de tipos diferentes de interferon-alf a, 2A e 2B para um mesmo paciente.

\begin{tabular}{|ll|}
\hline Data & Laboratório/tipo interferon \\
\hline$\bullet 05 / 08 / 99$ a 02/01/00 & $\bullet$ Roche / 2A \\
$\bullet$ 03/01/00 a 18/07/00 & $\bullet$ Cristália / 2A e 2B \\
$\cdot$ 19/07/00 a 23/11/00 & $\bullet$ Blausiegel / 2A e 2B \\
$\cdot 24 / 11 / 00$ a 20/12/00 & $\bullet$ Cristália / 2A e 2B \\
$\cdot 21 / 12 / 00$ a 28/12/00 & $\bullet$ Blausiegel / 2A e 2B \\
$\bullet 29 / 12 / 00$ a 28/02/02 & $\bullet$ Cristália / 2A e 2B \\
\hline
\end{tabular}

FIGURA 1 - Procedência e tipo do interferon

\begin{tabular}{|ll|}
\hline Data & Laboratório \\
\hline$\bullet 05 / 08 / 99$ a $07 / 02 / 00$ & $\bullet$ UCI Farma \\
$\bullet 05 / 05 / 00$ a $03 / 05 / 01$ & $\bullet$ Fiocruz \\
$\bullet 05 / 06 / 01$ & $\bullet$ UCI Farma \\
$\bullet 04 / 07 / 01$ a $28 / 02 / 02$ & $\bullet$ Fiocruz \\
\hline
\end{tabular}

FIGURA 2 - Procedência da ribavirina

A resposta ao tratamento foi classificada em: a) recaída, se deter minação qualitativa do VHC-RNA negativa ao final do tratamento e positiva 6 meses após; b) não-resposta, se determinação qualitativa do VHC-RNA positiva ao final do tratamento; c) resposta sustentada, se determinação qualitativa do VHC-RNA ne gativa ao final do tratamento e após 6 meses.

Não se determinou a carga viral devido ao exame não estar disponível no período do estudo.

Todas as biopsias foram re visadas pelo mesmo patologista, tendo sido empregadas para confecção das lâminas as colorações de hematoxilina-eosina e Gomory. Os cortes foram avaliados quanto ao grau de alterações histopatológicas segundo a classificação de 
GAYOTTO et al. ${ }^{(9)}$, que varia de 0 a 4 e tem correlação com a classificação METAVIR(12). Uma amostra aleatória de $10 \%$ do material foi encaminhada para controle interno e externo.

Para o teste anti-VHC utilizou-se a técnica ELISA de segunda geração (sensibilidade de $90 \%$ a $95 \%$ ) ou terceira (sensibilidade de $95 \%$ a $98 \%)^{(3)}$. Para realizar a determinação qualitativa do VHC-RNA, utilizou-se kit AMPLICOR ${ }^{\circledR}$ do laboratório ROCHE. Para genotipagem utilizou-se o método de hibridização reversa.

Delineou-se um estudo de coorte não-controlado. Definiu-se como desfecho principal a resposta sustentada ao tratamento, com relação à intenção e à conclusão do mesmo. Por intenção de tratamento, entende-se que fará parte da análise estatística todo paciente que iniciou o estudo. Conclusão de tratamento exclui os pacientes que não terminaram o tratamento proposto ${ }^{(5)}$.

Para a análise estatística dos resultados utilizaram-se os testes paramétricos t de Student (através do software "Primer of Biostatistics") ${ }^{(10)}$ e os não-paramétricos Qui-quadrado e Exato de Fisher (pelo software Epi Info $)^{(4)}$. O nível de significância (probabilidade de significância) adotado foi menor que $5 \%(P<0,05)$.
O projeto deste trabalho foi analisado e aprovado pela Comissão de Ética em Pesquisa em Seres Humanos do Hospital de Clínicas da UFPR.

\section{RESULTADOS}

\section{Clínicos e demográficos}

Dos 102 pacientes elegíveis para este estudo, excluíram-se 15: 12 não tinham determinação qualitativa do VHC-RNA pré-tratamento e em 3 não havia dados disponíveis no prontuário médico. Foram, então, incluídos 87 pacientes, tendo-se encontrado os seguintes resultados (Tabela 3): a) idade média de 42,7 anos; b) predomínio significativo do sexo masculino $(72,4 \%)$; c) entre os $67(77 \%)$ pacientes avaliados quanto ao genótipo, encontrou-se número significativamente maior de casos com genótipo 1 (53,7\%), contra $4,5 \%$ e $41,8 \%$ de pacientes com genótipos 2 e 3, respectivamente; d) quanto aos dados histológicos, observou-se ausência de fibrose em $6(5,2 \%)$ e cirrose em apenas $11(14,1 \%)$ dos 87 pacientes. Entre

TABELA 3 - Avaliação geral dos dados em relação à intenção de tratar e a conclusão do tratamento

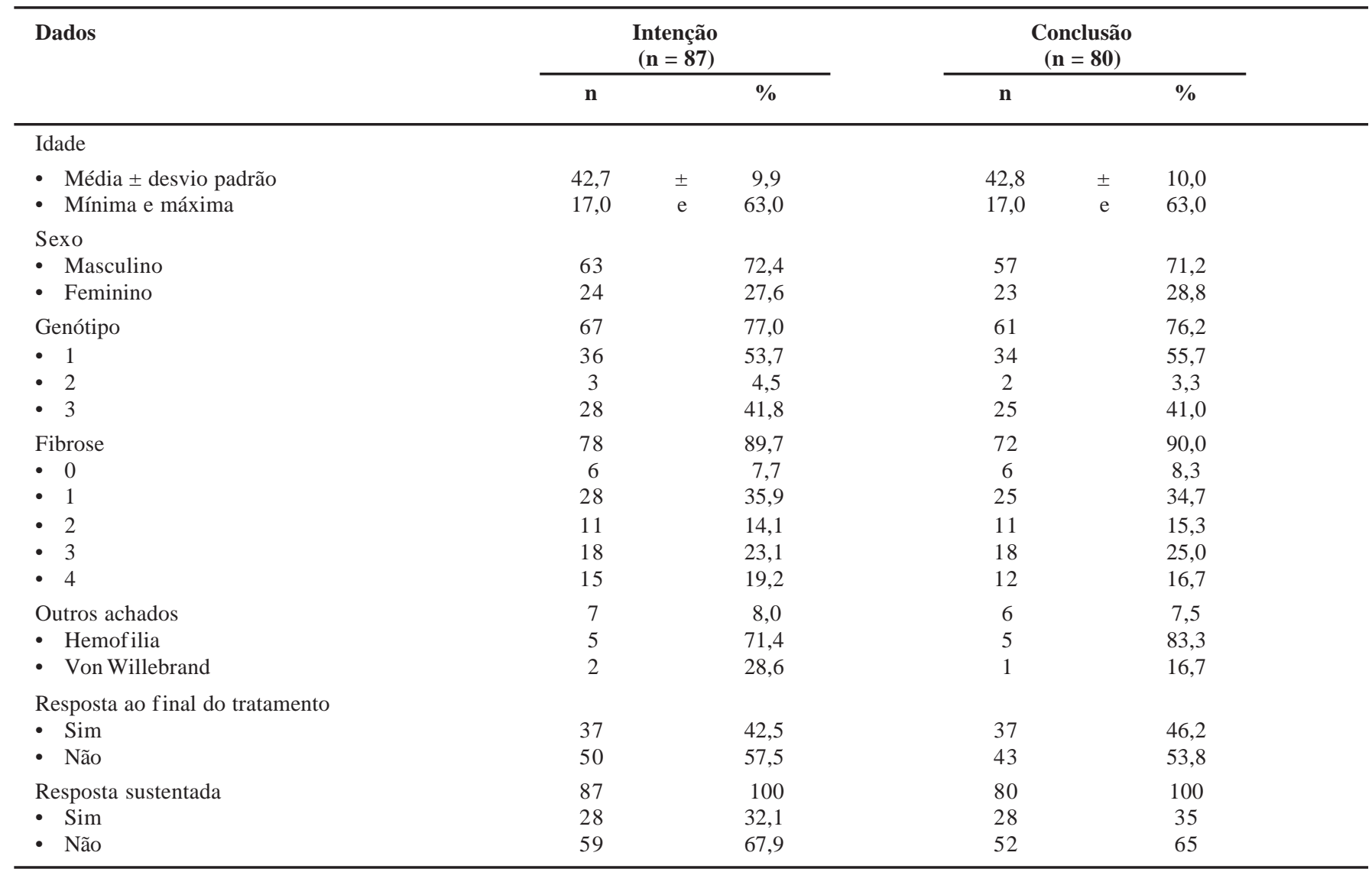


os que tinham fibrose, houve predomínio de casos com fibrose grau $1(35,9 \%)$

Vinte pacientes (23\%) não realizaram genotipagem do VHC prétratamento, devido à indisponibilidade do exame no período em que foram incluídos.

Cinco pacientes não foram submetidos a biopsia hepática porque três eram hemofílicos e dois tinham doença de Von Willebrand.

\section{Resposta viral sustentada}

Considerando-se intenção e conclusão de tratamento, a taxa de resposta viral sustentada foi de $32,1 \%$ (28 de 87 pacientes) e $35 \%$ (28 de 80 pacientes), respectivamente (Tabelas 3,4 ).

\section{Fatores independentes associados à resposta viral sustentada}

Correlacionando os fatores independentes de melhor resposta ao tratamento, ou seja, sexo feminino, idade inferior a 40 anos, genótipo diferente de 1 e grau de fibrose 0 ou 1 , encontrou-se significância estatística apenas com relação ao genótipo dos pacientes. Entre os pacientes com resposta viral sustentada, houve predomínio significativo do genótipo 3 (65\%), e entre os não-respondedores predomínio do genótipo $1(68,3 \% ; P=0,0184)$ (Figura 3).
A diferença da distribuição dos demais fatores não foi significativa.

\section{Estudo das perdas}

Sete $(6 \%)$ pacientes interromperam o tratamento: três $(42,8 \%)$ por sintomas gripais, um $(14,3 \%)$ por neoplasia de esôfago diagnosticada durante o tratamento, e três $(42,8 \%)$ por alterações hematológicas (Tabela 5).

\section{DISCUSSÃO}

Resposta sustentada. Os interferons pertencem à superfamília das citocinas. Modulam a atividade de muitos componentes do sistema imunológico, aumentando a capacidade do organismo de combater agentes infecciosos. Formam a primeira linha de defesa contra infecções virais. Classif icam-se em alfa, beta e gama, de acordo com a seqüência de aminoácidos dessas proteínas. O interferon-alfa é produzido por monócitos e células B em resposta a vírus e estímulos antigênicos. O interferon recombinante é produzido por técnicas de DNA recombinante em Escherichia coli. Duas formas de interferonalfa recombinante são comercialmente disponíveis e diferem por um único aminoácido na posição 23: lisina no interferon-alfa-2A e arginina no interferon-alfa- $2 \mathrm{~B}^{(28)}$.

TABELA 4 - Resposta sustentada vs. não-resposta

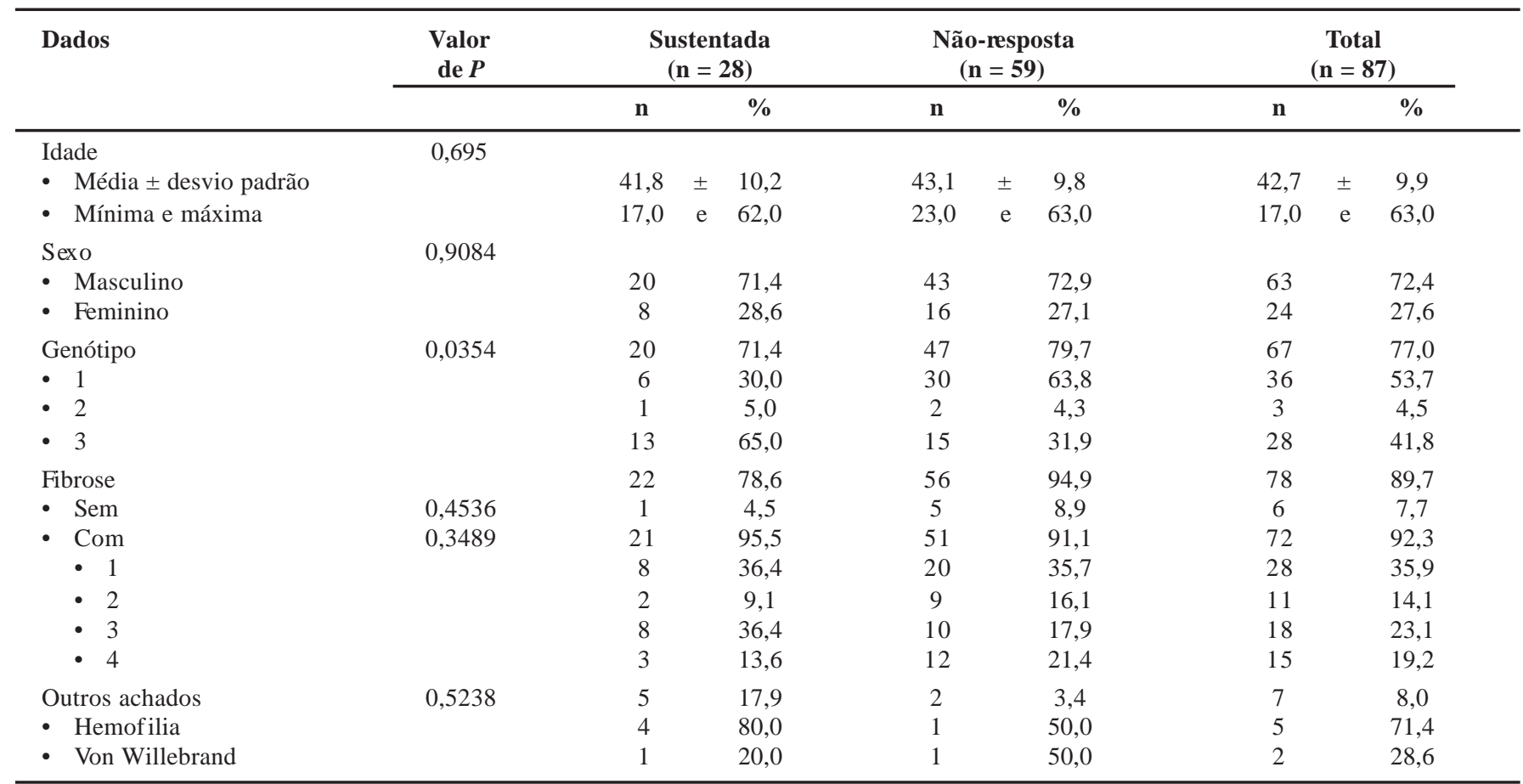




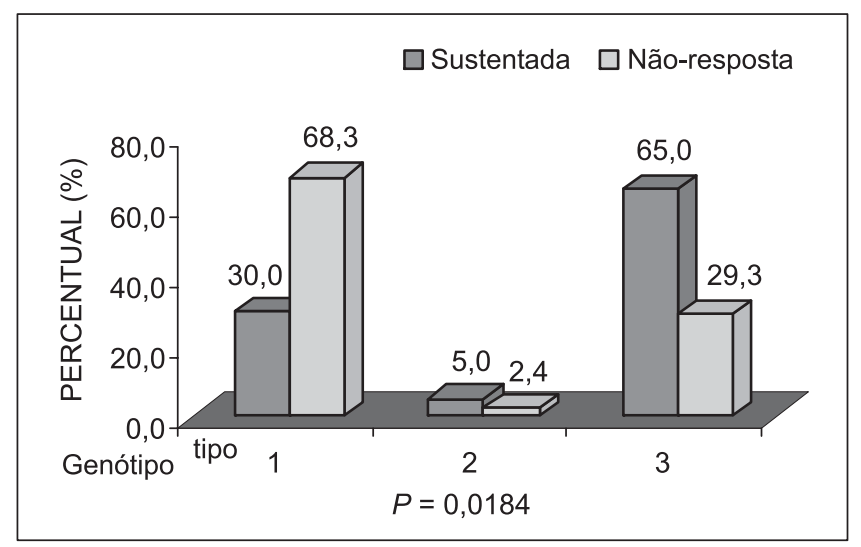

FIGURA 3 - Relação entre resposta e genótipo

TABELA 5 - Dados dos pacientes que interromperam o tratamento

\begin{tabular}{|c|c|c|c|c|c|}
\hline \multicolumn{6}{|c|}{ Tratamento interrompido (7 pacientes) } \\
\hline Motivo da inter rupção & & $\begin{array}{l}\text { - Alteração hematológica } \\
\text { - Efeitos colaterais } \\
\text { - Leucopenia } \\
\text { - Neoplasia esofágica } \\
\text { - Plaquetopenia }\end{array}$ & $\begin{array}{l}1 \\
3 \\
1 \\
1 \\
1\end{array}$ & & $\begin{array}{l}14,3 \\
42,8 \\
14,3 \\
14,3 \\
14,3\end{array}$ \\
\hline Idade & $\rightarrow$ & $\begin{array}{l}\text { - Média } \pm \text { desvio padrão } \\
\text { - Mínima e máxima }\end{array}$ & $\begin{array}{l}41,9 \\
29,0\end{array}$ & $\begin{array}{l} \pm \\
\mathrm{e}\end{array}$ & $\begin{array}{c}9,7 \\
54,0\end{array}$ \\
\hline Sexo & $\rightarrow$ & $\begin{array}{l}\text { - Masculino } \\
\text { - Feminino }\end{array}$ & $\begin{array}{l}6 \\
1\end{array}$ & & $\begin{array}{l}85,7 \\
14,3\end{array}$ \\
\hline Genótipo $(n=6)$ & $\rightarrow$ & $\begin{array}{l}\cdot 1 \\
\cdot 2 \\
\cdot 3\end{array}$ & $\begin{array}{l}2 \\
1 \\
3\end{array}$ & & $\begin{array}{l}33,3 \\
16,7 \\
50,0\end{array}$ \\
\hline Fibrose $(n=6)$ & $\rightarrow$ & $\begin{array}{l}\text { - } 1 \\
\text { - } 4\end{array}$ & $\begin{array}{l}3 \\
3\end{array}$ & & $\begin{array}{l}50,0 \\
50,0\end{array}$ \\
\hline Outros achados & $\rightarrow$ & - Von Willebrand & 1 & & 14,3 \\
\hline PCR Final tratamento & $\rightarrow$ & - Positivo & 7 & & 100,0 \\
\hline
\end{tabular}

Recentemente, foram desenvolvidos novos interferons, chamados peguilados. Têm a característica de serem metabolizados mais lentamente, devido à adição de uma cadeia de polietileno glicol a suas moléculas. Há dois interferons peguilados: um de $40 \mathrm{Kda}$ alfa- $2 \mathrm{~A}$, outro de $12 \mathrm{Kda}$, alfa-2B ${ }^{(7)}$. Estes interferons diferem quanto as suas propriedades físico-químicas, farmacocinéticas e farmacodinâmicas e, quando combinados à ribavirina, têm levado a taxas de cura acima de $50 \%{ }^{(7,8,22)}$. Cabe salientar que os resultados aqui descritos não são extrapoláveis aos interferons peguilados, haja vista as marcadas diferenças entre ambos e em relação aos interferons não-peguilados.

A ribavirina é um análogo de nucleotídio purínico, com efeito virostático contra largo espectro de vírus. Seus mecanismos de ação ainda são desconhecidos mas sugere-se que levem à inibição da RNA polimerase RNA-dependente e esgotamento do pool de guaninas ${ }^{(28)}$.

Os resultados do tratamento da hepatite crônica pelo VHC melhoraram de forma marcante com a terapêutica combinada do interferon-alfa com ribavirina. Metanálise recente de 48 estudos controlados, envolvendo 6.585 pacientes comparando o uso de interferon-alfa como monoterapia ou associado à ribavirina para tratamento da hepatite $\mathrm{C}$ crônica, demonstrou uma taxa geral de resposta sustentada de $37 \%$ em pacientes virgens de tratamento que receberam a associação dos dois medicamentos ${ }^{(14)}$. Nessa metanálise, os pacientes foram tratados com interferon-alfa- $2 \mathrm{~A}$ ( 5 estudos), alfa-2B (25 estudos) ou não citavam o tipo de interferon 
utilizado (18 estudos). A procedência dos medicamentos, quando citada, era dos laboratórios Roche (alfa-2A) ou Schering-Plough (alfa-2B).

Outra revisão sistemática de 19 estudos randomizados envolvendo 3.765 pacientes, tratados com interferon-alfa e ribavirina pela primeira vez, encontrou $33 \%$ de resposta sustentada à terapia combinada ${ }^{(13)}$.

Entre estes diversos estudos não foi citada a altemância de medicamentos de diferentes procedências ou de diferentes tipos de interferons. Pode-se questionar como um dos inconvenientes da alternância de medicamentos, a capacidade do interferon-alfa-2A de induzir a produção de maiores títulos de anticor pos neutralizantes, ou seja, anticorpos contra o próprio interferon, do que o interferonalfa-2B ${ }^{(28)}$, o que poderia hipoteticamente afetar a resposta aos interferons. No entanto, este ponto de vista é refutado por evidências contrárias à impor tância destes anticorpos na resposta ao tratamento ${ }^{(29)}$.

As taxas de resposta sustentada obser vadas neste estudo $(32,1 \%)$ foram muito aproximadas àquelas observadas pela literatura mundial $(33 \% \text { a } 37 \%)^{(13,14)}$. Assim sendo, ainda que o tratamento da hepatite crônica pelo VHC pelo sistema de saúde público brasileiro acarrete o uso de interferons-alfa e ribavirinas de diferentes procedências e que inclua a possibilidade do uso alternado de dois tipos de interferons, estas variáveis mostraram não afetar os resultados esperados.

Preditores. POYNARD et al. ${ }^{(25)}$ demonstraram que os fatores independentes relacionados à melhor resposta ao tratamento eram sexo feminino, idade inferior a 40 anos, fibrose leve ou ausência de fibrose, genótipos 2 ou 3 e carga viral menor que 3,5 milhões de cópias $/ \mathrm{mL}$. Esses autores observaram resposta viral sustentada em $30 \%$ dos pacientes com genótipo 1 e de $64 \%$ naqueles com genótipos 2 e 3 .
No presente estudo observou-se também cor relação significativa $(70 \%)$ entre os genótipos 2 e 3 com a resposta sustentada. Não se observou, porém, correlação com o sexo e idade, mas isto pode ter ocorrido devido ao predomínio significativo de pacientes masculinos e com idade superior a 40 anos na população selecionada para o estudo.

Metanálise publicada em 1999 envolvendo 344 pacientes demonstrou maiores taxas de resposta sustentada no grupo de pacientes que não tinha cirrose ${ }^{(26)}$. Essa cor relação com cirrose ou com outros graus de fibrose não foi encontrada nesta série. Não há dados que justifiquem este achado na população estudada no presente estudo.

\section{CONCLUSÕES}

A taxa de resposta sustentada encontrada neste estudo é compatível com a da literatura internacional, apesar das freqüentes variações individuais quanto aos tipos de interferons e a procedência dos mesmos.

Entre os preditores de eficácia mencionados na literatura internacional, apenas a presença dos genótipos 2 e 3 mostrou-se igualmente indicativa de boa resposta na presente série.

\section{AGRADECIMENTO}

À Sra. Deise Pontarolli, do setor de Medicamentos Excepcionais da Central de Medicamentos da Secretaria de Saúde do Estado do Paraná, pelas informações prestadas sobre os medicamentos fornecidos no período deste estudo.

Acras RN, Pedroso MLA, Caum LC, Pisani JC,Amarante HMBS, Car mes ER. The sustained response rates for chronic hepatitis C patients undergoing therapy with the se veral interferons and ribavarins supplied by Brazilian's Health Ministry is comparable to those repor ted in the literature. Arq Gastroenterol 2004;41(1):3-9

ABSTRACT - Background - The sustained response rates of chronic hepatitis C therapy to interferons alpha 2A and 2B associated to ribavirin are described as approximatel y $40 \%$. Nevertheless, studies on the sustained response rates in a setting of frequent changes of type of interferon as well as of supplies of interferons and ribavirin are lacking. Aims - To e valuate the pre valence of sustained response and to determine the predictors of response to chronic hepatitis C therapy, in a cohort of outpatients at Curitiba, PR, south Brazil, in a setting of heterogeneous therapy re garding type and supply of the medications. Population and Methods - A cohort of 87 chronic hepatitis C patients submitted to therapy with interferon alpha 2 and ribavirin were followed from August 1999 to August 2002. The prevalence of sustained response and the influence of gender, age, genotype and severity of liver fibrosis in the response were evaluated. Results - A sustained response prevalence of $32.1 \%$ was found positively associated to genotypes 2 and 3 . Conclusions Despite the frequent changes on product type and/or procedence, the sustained response prevalence rate found in this study was similar to that described in the literature.

HEADINGS - Chronic hepatitis C. Interferons. Ribavirin.

\section{REFERÊNCIAS BIBLIOGRÁFICAS}

1. Brasil. Ministério da Saúde. Portaria 639. Anexo I: Protocolo clínico e diretrizes terapêuticas da hepatite viral crônica tipo C. Diário Oficial da União, Brasilia, DF., 26 jun 2000. p. 34.
2. Choo Q-L, Kuo G, Weiner AJ, Overley LR, Bradley DW, Houghton M. Isolation of a cDNA clone from a blood-borne non-A non-B viral hepatitis genome. Science 1989;244:359-62.

3. Davis G. Hepatitis C. In: Schif f E, editor. Liver disease. Philadelphia: LippincotRaven; 1999. p.793-825. 
Acras RN, Pedroso MLA, Caum LC, Pisani JC, Amarante HMBS, Carmes ER. A taxa de resposta sustentada da hepatite C crônica ao tratamento com os diversos interferons-alfa e ribavirinas distribuídos pelo governo brasileiro é semelhante à da literatura mundial

4. Epi Info, version 6.04b. A word processing, database and statistics program for public health [computer program]. Atlanta, GA: Centers for Disease Control \& Prevention; January 1997.

5. Fergusson D, Aaron S, Guyatt G, Herbert P. Post randomization exclusions: the intention to treat principle and excluding patients from analysis. BMJ 2002;325:652-4.

6. Forns X, Ampurdanes S, Llovet J, Aponte J, Quintó L, Martinez-Bauer E, Bruguera M, Sánchez-Tapias J, Rodes J. Identification of chronic hepatitis C patients without hepatic fibrosis by a simple predictive model. Hepatology 2002;36:986-92

7. Foster GR. Pe gylated interferon with ribavirin therapy for chronic infection with the hepatitis C virus. Expert Opin Pharmacother 2003;4:685-91

8. Fried M, Shiffman M, Reddy R, Smith C, Marinos G, Gonçales Jr F, Haussinger D, Diago M, Caroni G, Dhumeaux D, Craxi A, Lin A, Hoffman J, Yu J. Peg interferon- $\alpha-2 \mathrm{~A}$ plus ribavirin for chronic hepatitis $\mathrm{C}$ virus infection. $\mathrm{N}$ Engl $\mathrm{J}$ Med 2002;347:975-82.

9. Gayotto LC e Comitê SBP-SBH. Visão histórica e consenso nacional sobre a classif icação das hepatites crônicas. Projeto do Clube de Patolo gia Hepática da Sociedade Brasileira de Patologia aprovado pela Sociedade Brasileira de Hepatolo gia. GED Gastroenterol Endosc Dig 2000;19:137-40.

10. Glantz S. Primer of biostatistics. 4th ed. New York: McGraw Hill; 1997.

11. Hepatitis C--global pre valence (update). Wkly Epidemiol Rec 2000;75(3):18-9

12. Intraobserver and interobserver variations in liver biopsy interpretation in patients with chronic hepatitis C. The French METAVIR Cooperative Study Group. Hepatolo gy 1994;20(1 Pt 1):15-20.

13. Kjaergard L, Krogsgaard K, Gluud C. Interferon alpha with or without ribavirin for chronic hepatitis $\mathrm{C}$ : systematic review of randomized trials. BMJ 2001;323:1151-5.

14. Kjaergard LL, Krogsgaard K, Gluud C. Ribavirin with or without alpha interferon for chronic hepatitis C [update of: Cochrane Database Syst Rev 2002;(1):CD002234] Cochrane Database Syst Rev 2002;(2):CD002234.

15. Koretz RL Decisions, decisions, decisions. Gastroenterology 2000;118:1268-70.

16. Lauer G, Walker B. Hepatitis C virus infection. N Engl J Med 2001;354:41-52

17. Liang TJ, Rehermann B, Seeff LB, Hoofnagle JH. Patho genesis, natural history, treatment, and pre vention of hepatitis C. Ann Intern Med 2000;132:296-305.

18. Marcellin P, Boyer N, Ger vais A, Mar tinot M, Pouteau M, Castelnau C, Kilani A, Areias J, Auperin A, Benhamou JP, Degott C, Erlinger S. Long-term histologic improvement and loss of detectable intrahepatic HCV RNA in patients with chronic hepatitis $\mathrm{C}$ and sustained response to interferon-alpha therapy. Ann Intern Med 1997;127:875-81.
19. McHutchison JG, Gordon SC, Schiff ER, Shiffman ML, Lee WM, Rustgi VK, Goodman ZD, Ling MH, Cort S, Albrecht JK. Interferon alfa 2B alone or in combination with ribavirin as initial treatment for chronic hepatitis C. Hepatitis Interventional Therapy Group. N Engl J Med 1998;339:1485-92.

20. Myers RP, Regimbeau C, Thevenot T, Leroy V, Mathurin P, Opolon P, Zarski JP, Poynard T. Interferon for interferon naive patients with chronic hepatitis $\mathrm{C}$. Cochrane Database Syst Rev; (2):CD000370, 2002

21. National Institutes of Health Consensus Development Conference Pane statement: management of hepatitis C. Hepatology 1997;26 (3 Suppl 1):2S-10S.

22. Pedder SC. Pegylation of interferon alpha: structural and pharmacokinetic properties. Sem Liver Dis 2003;1 Suppl 23:19-22.

23. Poynard T, Leroy V, Cohard M. Meta analysis of interferon randomized trials in the treatment of viral hepatitis, effects of dose and duration. Hepatology 1996;24:778-89

24. PoynardT, Marcellin P, Lee S, Niederau C, Minuk G, Ideo G, Bain V, Heathcote J, Zeuzem S, Trepo C, Albrecht J. Randomized trial of interferon 2B plus ribavirin for 48 weeks or for 24 weeks versus interferon $2 b$ plus placebo for treatment of chronic infection with hepatitis C virus. Lancet 1998;352:1426-32.

25. Poynard T, McHutchison J, Goodman Z, Ling MH, Albrecht J. Is an "a la car te combination interferon $2 \mathrm{~B}$ plus ribavirin re gimen possible for the first line treatment in patients with chronic hepatitis C? The ALGOVIRC Project Group. Hepatology 2000;31:211-8

26. Schalm S, Weiland O, Hansen B, Milella M, Lai M, Hollander A, Michielsen P Belloleuono A, Chemello L, Pastore G, Chen D, Brouwer J. Interferon-ribavirin for chronic hepatitis $\mathrm{C}$ with and without cirrhosis: analysis of individual patient data of six controlled trials. Gastroenterology 1999;117:408-13.

27. Shepherd J, Waugh N, Hewitson P. Combination therapy (interferon alfa and ribavirin) in the treatment of chronic hepatitis $\mathrm{C}$ : a rapid and systematic review. Health Technol Assess 2000;4(33):1-67.

28. Silva LC. Drog as utilizadas no tratamento das hepatites crônicas. Alguns aspectos far macológicos. In: Silva LC, editor. Hepatites agudas e crônicas. 2.ed. São Paulo: Sarvier;1995. p.273-81

29. Stancek D, Fuchsberger N, Oltman M, Schmeisser H, Kontsek P, Jahnová E, Hajnická V. Signif icance of anti-interferon-alpha2 and sICAM-1 activities in the sera of viral hepatitis $B$ and $C$ patients treated with human recombinant interferonalpha2. Acta Virol 2001;45:287-92.

Recebido em 6/2/2003 Aprovado em 25/9/2003 